Reprod. Nutr. Dévelop., 1986, 26 (1 B), 309-310.

\title{
Effets de l'addition de matières grasses non protégées à la ration de la vache laitière sur la concentration et la composition chimique des bactéries et des protozoaires du rumen
}

\author{
D. BAUCHART, F. LEGAY-CARMIER, M. DOREAU $(*)$, J.-P. JOUANY $\left({ }^{* *}\right)$
}

Laboratoire d'Etude du Métabolisme énergétique.

(*) Laboratoire de la Lactation.

(**) Laboratoire de la digestion des Ruminants, I.N.R.A. Theix, 63122 Ceyrat, France.

Summary. Average amounts of total solid-adherent bacteria (SAB) and liquid associatedbacteria $(L A B)$ in the rumen amounted to 391 and $153 \mathrm{~g}$ respectively $(P<0.05)$ and their fatty acid (FA) contents were 10.5 and $4.3 \mathrm{~g} / 100 \mathrm{~g} \mathrm{DM}$ respectively $(\mathrm{P}<0.05$ ) in dairy cows fed a hay and concentrate $(50 / 50)$ diet. When the diet was supplemented with unprotected rapeseed oil ( 5 or $10 \%$ of DM) or tallow ( $10 \%$ of DM), the amounts of bacteria were not modified significantly but their FA contents increased by 54,58 and $95 \%$ for the $\operatorname{LAB}(P<0.05)$ and 74,84 and $96 \%$ for the SAB $(P<0.05)$. There were no significant effects in the $\mathrm{Nt}$ and $\mathrm{N}_{\mathrm{ARN}} / \mathrm{Nt}$ content of bacteria. Lipid supplemented diets decreased the number of protozoa by 35,46 and $39 \%$ respectively $(P<0.01)$ but induced an increase in their lipid content as in bacteria.

L'addition de fortes quantités de matières grasses dans la ration des ruminants peut réduire l'intensité des fermentations dans le rumen par un effet de toxicité des chaînes grasses ou une réduction de l'action des microorganismes sur les particules alimentaires. Par contre, on ne dispose que de très rares informations sur l'effet des matières grasses sur la quantité et la composition chimique des bactéries et des protozoaires du rumen.

Matériel et méthodes. Quatre vaches Pie noires, en période de lactation, équipées d'une canule du rumen, ont reçu en carré latin 4 rations constituées en proportions égales de foin de fétuque et d'aliment concentré : une ration témoin (T) et des rations contenant par rapport à la MS, 5 (C5) et $10 \%$ (C10) d'huile de colza et $10 \%$ (Su10) de suif (imprégnés sur de la pulpe de betterave).

Les contenus de rumen prélevés $1 / 2 \mathrm{~h}$ avant puis 2,4 et $6 \mathrm{~h}$ après la distribution du repas du matin, ont été réunis puis les phases liquide et solide ont été séparées sur une toile métallique. Les bactéries adhérant à la phase solide (BAS) ont été extraites par battage au "stomacher " (Merry et Mc Allan, 1983) puis purifiées par centrifugation, de même que les bactéries associées à la phase liquide (BAL). Après comptage, les protozoaires ont été purifiés à partir de la phase liquide par décantation à $40^{\circ} \mathrm{C}$ puis filtration sur des tamis de nylon. Le poids total de phase solide et le volume total de phase liquide du rumen ont été déterminés à partir de vidage complet du rumen. Les lipides des bactéries et des protozoaires ont été extraits, à partir d'échantillons lyophilisés, par le mélange chloroforme-méthanol $(2 / 1)(\mathrm{V} / \mathrm{V})$ puis par l'hexane- $\mathrm{HCl}$, et leurs acides gras $(A G)$ analysés par CPG en présence d'étalon interne. Les teneurs en $N$ et en ARN 
(bases puriques) ont été déterminées, à partir des mêmes échantillons, par les méthodes de Kjeldhal et de Zinn et Owens (1980) respectivement.

Résultats et discussion. Pour tous les régimes, les bactéries fixées (BAS) représentent 72 à $80 \%$ des bactéries totales récupérées $(P<0,05)$ et leur teneur en $A G$ est 2,4 à 3 fois supérieure à celle des bactéries libres (BAL). La supplémentation en lipides des régimes entraîne une augmentation des teneurs en $A G$ des deux types bactériens $(+96 \%$ pour le régime Su10, $\mathrm{P}<0,05)$, mais ne modifie pas significativement les quantités de BAS et BAL dans le rumen (tabl. 1). Les teneurs en $\mathrm{N}$ total et $\mathrm{N}_{\mathrm{ARN}} / \mathrm{Nt}$ des $\mathrm{BAL}$ sont légèrement supérieures à celles des BAS comme l'avaient observé Merry et Mc Allan (1983) mais sont peu influencées par les régimes.

La réduction du nombre de protozoaires avec les régimes contenant $10 \%$ de lipides $(-46$ et $-39 \%, P<0,01)$ diffère de la disparition totale observée chez le Mouton recevant de l'huile de lin (lkwuegbu et Sutton, 1982). Les régimes enrichis en matières grasses semblent accroître les teneurs en lipides et en $\mathrm{N}$ des protozoaires (mesurées sur 2 vaches) mais ne modifient pas le rapport $\mathrm{N}_{\mathrm{ARN}} / \mathrm{Nt}$ (tabl. 1).

TABL. 1. - Quantité et composition chimique des microorganismes du rumen selon les rations.

\begin{tabular}{|c|c|c|c|c|c|c|c|c|}
\hline \multirow{2}{*}{ Bactéries } & \multicolumn{4}{|c|}{ BAL } & \multicolumn{4}{|c|}{ BAS } \\
\hline & $\mathrm{T}$ & $\mathrm{C} 5$ & $\mathrm{C} 10$ & Su10 & $\mathrm{T}$ & $\mathrm{C} 5$ & C10 & Su10 \\
\hline \multirow{5}{*}{$\begin{array}{l}\text { g } \mathrm{MS} / \text { contenu } \\
\text { rumen } \\
\mathrm{g} \mathrm{MS/kg} \mathrm{MS} \\
\text { ingéré } \\
\mathrm{AG} \% \mathrm{MS} \\
\mathrm{N} \text { total \% MS } \\
\mathrm{N}_{\mathrm{ARN}^{*} / \mathrm{N} \text { total }}\end{array}$} & $153^{\mathrm{a}}$ & $137^{a}$ & $140^{\mathrm{a}}$ & $117^{a}$ & $391^{b}$ & $454^{b}$ & $530^{\mathrm{b}}$ & $492^{b}$ \\
\hline & $10,3^{a}$ & $8,6^{a}$ & $8,4^{a}$ & $7,4^{a}$ & $25,3^{b}$ & $27,7^{b}$ & $31,6^{\mathrm{b}}$ & $31,2^{b}$ \\
\hline & $4,3^{a}$ & $6,0^{\mathrm{b}}$ & $6,8^{b c}$ & $8,4^{b c}$ & $10,5^{c}$ & $18,3^{d}$ & $19,3^{d}$ & $20,6^{d}$ \\
\hline & $6,6 b c$ & $7,1^{\mathrm{bc}}$ & $6,6^{c}$ & $7,1 \mathrm{c}$ & $6,6^{\mathrm{bc}}$ & $6,0^{a b}$ & $5,5^{\mathrm{a}}$ & $5,5^{\mathrm{ab}}$ \\
\hline & $0,214^{a}$ & $0,155^{\mathrm{ab}}$ & $0,179^{a}$ & $0,181^{a}$ & $0,124^{b c}$ & $0,131^{\mathrm{ac}}$ & $0,149^{a}$ & $0,150^{a}$ \\
\hline Protozoaires & $\mathrm{T}$ & C5 & C10 & Su10 & \multirow{2}{*}{\multicolumn{4}{|c|}{ 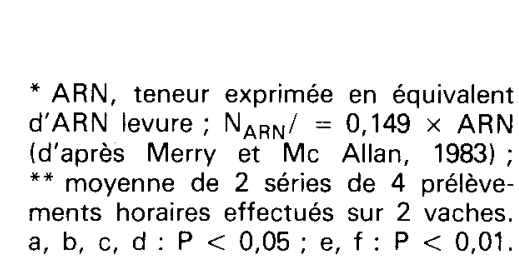 }} \\
\hline $\begin{array}{l}10^{5} / \mathrm{ml} \text { jus } \\
\text { rumen** } \\
\text { Lipides \% MS } \\
\text { AG \% MS } \\
\mathrm{N} \text { total } \% \text { MS } \\
\mathrm{N}_{\text {ARN }}^{*} / \mathrm{N} \text { total }\end{array}$ & $\begin{array}{l}2,6^{\mathrm{e}} \\
3,6 \\
2,2 \\
2,9 \\
0,126\end{array}$ & $\begin{array}{l}1,7^{\text {ef }} \\
6,3 \\
3,5 \\
4,9 \\
0,102\end{array}$ & $\begin{array}{l}1,4^{f} \\
5,7 \\
2,5 \\
4,1 \\
0,111\end{array}$ & $\begin{array}{l}1,6^{f} \\
4,7 \\
3,1 \\
4,5 \\
0,134\end{array}$ & & & & \\
\hline
\end{tabular}

Avec ces régimes, l'accroissement de la teneur en lipides des bactéries soulève le problème de la nature et du lieu de dépôt de ces lipides (en cours d'étude). Les fortes différences de teneur et de composition entre les bactéries BAS et BAL dans le rumen, amplifiées avec les régimes enrichis en lipides, posent avec acuité le problème de la représentativité des BAL pour la quantification des composés bactériens dans le flux duodénal.

Ikwuegbu O. A., Sutton J. D., 1982. The effect of varying the amount of linseed oil supplementation on rumen metabolism in sheep. Br. J. Nutr., 48, 365-375.

Merry R. J., Mc Allan A. B., 1983. A comparison of the chemical composition of mixed bacteria harvested from the liquid and solid fractions of rumen digesta. Br. J. Nutr., 50, 701-709.

Zinn R. A., Owens F. N., 1980. Rapid procedure for quantifying nucleic acid content of digesta. In : Protein Symp., Oklahoma State Univ., 26-30. 